\title{
Effect of CuI Anode Buffer Layer on the Growth of Polymers Thin Films and on the Performances of Organic Solar Cells*
}

\author{
Pedro Pablo Zamora ${ }^{1}$, Fernando Raul Díaz ${ }^{1 \#}$, Maria Angelica del Valle ${ }^{1}$ Linda Cattin², Guy Louarn², \\ Jean Christina Bernède ${ }^{3}$
}

${ }^{1}$ Facultad de Química, Pontificia Universidad Católica de Chile, Santiago, Chile; ${ }^{2}$ Institut des Matériaux Jean Rouxel (IMN), Centre National de la Recherche Scientifique, Université de Nantes, Nantes, France; ${ }^{3}$ MOLTECH, Centre National de la Recherche Scientifique, Université de Nantes, Nantes, France.

Email: ${ }^{*}$ diaz@uc.cl

Received November $29^{\text {th }}, 2012$; revised January $6^{\text {th }}, 2013$; accepted January $21^{\text {st }}, 2013$

\begin{abstract}
Organic photovoltaic cells using polymer belonging to the aniline-heteroaryl family as electron donor have been achieved by thermal evaporation. We show that the properties of the polymer film, morphology, molecule order and conductivity depend strongly on the bottom anode buffer layer. While cells without anode buffer layer or with $\mathrm{MoO}_{3}$ or $\mathrm{CuI}$ anode buffer layer have been probed, we show that CuI allows improving strongly the cells efficiency through an improvement of the morphology and conductivity of the polymer film. This shows that although it is necessary a good band matching at the interface, this is not sufficient, because the templating effect of $\mathrm{CuI}$ on the polymer film is primordial for photovoltaic cells improvement.
\end{abstract}

Keywords: Organic Solar Cells; Vacuum Thermal Evaporation; Conjugated Polymers; Aniline-Heteroaryl Polymers

\section{Introduction}

Conjugated organic polymers have been of great interest as an important class of electronic materials because of their high electrical conductivities [1]. Polyaniline is one example which has received a great interest and has been employed in a number of commercial applications [1-4], however, it has no photovoltaic properties due to inadequate band gap for these applications. On the other hand, furan and thiophene are two of the five-membered heteroaromatic ring compounds that have been extensively studied in terms of its reactivity, its specific physicochemical properties, and its technological applications [5-10]. It has attracted particular attention, due to its low band gap value, notwithstanding due to high oxidation potential, difficulty which many authors have overcome by changing the substituents in furan and thiophene rings. In addition, various, co-polymers and biopolymers [11-13] based on polyfuranes and polythiophenes show good stability.

Furan/aniline and Thiophene/aniline based polymers, as poly 4-(2-furanyl)-aniline (P4,2FA) and poly 4-(3furanyl)-aniline (P4,3FA) 4-(2-thiophenyl)aniline (P4,2TA) and 4-(3-thiophenyl)aniline (P4,3TA), will exhibit a re-

\footnotetext{
*Special Issue-Solar Energy.
}

${ }^{\#}$ Corresponding author. duced $E g$. Consecuently these are materials with photoelectrical properties which could be employed in solar cells. Along with this it is possible to study the effect of different anode buffer layers in the photovoltaic yield when these polymers are used as electron donor in photovoltaic devices.

Organic photovoltaic is nowadays one of the most investigated research field, because of low cost and low temperature process [14]. Smart chemistry can design conjugated polymeric structures for organic photovoltaic cells (OPVCs) and progress has been made in recent years. Nevertheless, most of the materials designed today suffer from the disadvantage of low carrier mobility, which limits the short circuit current of the cells and therefore their efficiency. To solve this problem, different approaches, such as thermal annealing or additives, have been used to improve the carrier mobility. A well know mean consists in the increase of the order present in the layer. The fundamental structure of OPVCs consists in the photoactive layer sandwiched between two electrodes [15]. The photoactive layer can be a bilayer of an electron donor (ED), and an electron acceptor (EA) or a bulk heterojunction consisting of a blend of the two types of organic semiconductors. Indium tin oxide (ITO) is commonly used as transparent conductive anode. In 
order to increase the anode work function, which is necessary for efficient hole collection, the ITO surface is subjected to specific treatments, such as oxygen plasma, or coated with a suitable anode buffer layer [16]. Metal, such as gold [17], but also transition metal oxides [18], such as tungsten oxide $\left(\mathrm{WO}_{3}\right)$ [19], molybdenum oxide $\left(\mathrm{MoO}_{3}\right)$ [20] and nickel oxide ( $\left.\mathrm{NiO}\right)$ [21] have been used as efficient anode buffer layer (ABL). If a lot of works have been dedicated to the improvement of the band matching at the interface anode/organic electron donor, no many works have been devoted to the possibility of templating the organic layer through the use of specific anode buffer layer. As a matter of fact it has been already shown that, in the case of small molecules, it is possible to modify the molecular orientation of the organic layer through the use of specific anode buffer, such as PTCDA [22], CuI [23-25]. In the present study, we show that this result can be generalized to polymers.

Two technological routes are mainly used to grow OPV cells, the deposition of polymers and nanoparticles from solution by spin coating technique and the vacuum sublimation of small molecules and oligomers [26]. The former route has given the concept of bulk heterojunction solar cells (BHJ) [27], while the later gives the multiheterojunction solar cells family [28]. Compared to spin coating deposition, sublimation under vacuum allows easy purification of organic material. High purity is critical not only for devices performances, but also for long device life time. In addition, vacuum deposition allows facile fabrication of multilayered devices and facile control of the layers thickness [29]. Moreover the templating effect of the substrate, if present, on the organic film structure is amplified by the vacuum deposition process, since in that case the organic material is deposited molecule by molecule onto the substrate. Recently, the vacuum thermal evaporation of poly (3-hexylthiophene) (P3HT) for application in photovolataic cells has been demonstrated [30,31]. In the present work we widen the field of application of the $\mathrm{CuI}$ as templating anode buffer layer to polymers deposited by vacuum sublimation. In order to put in evidence this effect of $\mathrm{CuI}$ on the growth of different organic film, we investigated multi-heterojunction solar cells. We show that for different polymers belonging to the aniline-heteroaryl family, a thin $\mathrm{CuI}$ buffer layer allows to enhance strongly the OPV cells performance through the improvement of the conductivity of the organic donor, via improvement of the optical absorbance and structural properties of these polymers.

\section{Experimental}

The chemical syntheses of monomers was made by Suzuki-Miyaura cross coupling between 4-bromoaniline and the heteroaryl boronic acid, respectively, in presence of $10 \mathrm{~mol} \% \mathrm{Pd} / \mathrm{C}$ as catalyst and potassium carbonate.
Subsequently, the monomers were purified and polymerized using $\mathrm{H}_{5} \mathrm{IO}_{6}$ and $\mathrm{HClO}_{4}$ as oxidizing agent mixture [32]. The polymers were dedoped using a solution of $\mathrm{NH}_{4} \mathrm{OH}(\mathrm{pH}=9)$ for $24 \mathrm{~h}$ under stir.

The characterizations of monomers and polymers structures were carried out using NMR and UV-vis spectroscopy. NMR spectra were recorded on a Bruker 400 $\mathrm{MHz}$ spectrophotometer using DMSO $\mathrm{d}_{6}$ as deuterated solvent UV-Vis measurements were carried out on a CARY $5 G$ spectrophotometer.

In the present work, OPVCs studied were the multiheterojunction: $\mathrm{ITO} / \mathrm{ABL} / \mathrm{ED} / \mathrm{C}_{60} / \mathrm{BCP} / \mathrm{Al}$. In these cells, fullerene $\left(\mathrm{C}_{60}\right)$ and $\mathrm{BCP}$ (bathocuproine) have been used as electron acceptor and exciton blocking layer (EBL), respectively. $\mathrm{C}_{60}$ is well known as a very efficient electron acceptor. Between the $\mathrm{C}_{60}$ and the aluminium cathode, the introduction of EBL improves significantly the OPV cells performances [33]. The ABL was either $\mathrm{CuI}, \mathrm{MoO}_{3}[34]$ or $\mathrm{MoO}_{3} / \mathrm{CuI}$. Also OPV Cells without ABL have been probed as reference. The different ED used were Poly(4-(2-thiophenaniline)) (P4,2TA), Poly (4-(2-furanylaniline)), (P4,2FA), Poly(4-(3-thiophenaniline)) (P4,3TA) and Poly(4-(3-furanylnaniline)), (P4,3FA) the schemes of these different polymers are presented in Figure 1.

Before thin films deposition, the ITO coated glass substrate was scrubbed with soap, rinsed with distilled water, dried and next placed in the vacuum chamber $\left(10^{-4} \mathrm{~Pa}\right)$. The ABL, ED, $\mathrm{C}_{60}$, BCP layers were deposited onto the substrate by sublimation and $\mathrm{Al}$ were deposited by high vacuum evaporation, without breaking the vacuum. The CuI layer thickness was $3 \mathrm{~nm}$, in the light of earlier works [23], while the $\mathrm{MoO}_{3}$ layer was $4 \mathrm{~nm}$ thick [35]. The thickness of the different ED layers has been optimized experimentally. It is, whatever the ED used, 15 $\mathrm{nm}$. Finally, the thickness of the ED, $\mathrm{C}_{60}$, and BCP films was $15 \mathrm{~nm}, 40 \mathrm{~nm}$ and $9 \mathrm{~nm}$ respectively. The deposition

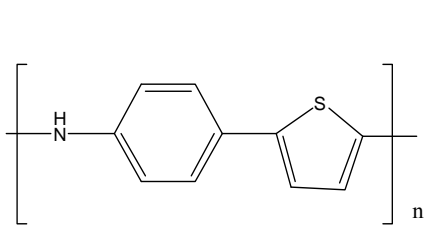

(a)

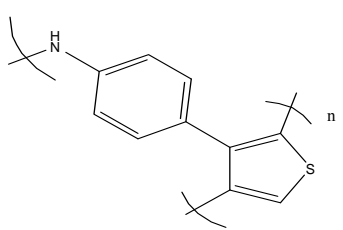

(c)

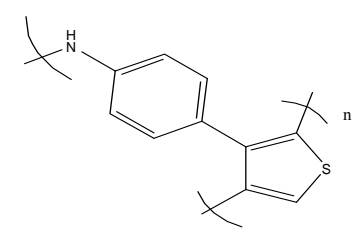

(b)

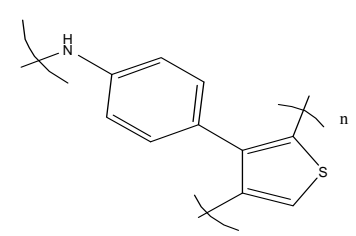

(d)
Figure 1. Schemes of the different EDs, (a) P4,2TA, (b) P4,3TA, (c) P4,2FA and (d) P4,3FA. 
rate of the organic material was $0.05 \mathrm{~nm} / \mathrm{s}$. The effecttive area of each cell was $0.16 \mathrm{~cm}^{2}$. The thin films thick- nesses and deposition rates were estimated in situ using a quartz monitor. Finally, the cell arrangement was:

$$
\text { glass } / \mathrm{ITO}(100 \mathrm{~nm}) / \mathrm{ABL} / \mathrm{ED} / \mathrm{C}_{60}(40 \mathrm{~nm}) / \operatorname{BCP}(9 \mathrm{~nm}) / \operatorname{Al}(100 \mathrm{~nm})
$$

All the chemical products have been provided by Aldrich except for the ED, which have been synthesized in the Pontificia Universidad Católica de Chile, while the ITO glass coated have been provided by SOLEMS, France. The chemical products form Aldrich were used without any purification, the monomer synthesized were purified by chromatography column and crystallization then were polimerizated and used as ED in the OPV (a new purification occurred) Indeed, it has been shown that, using the same charge in the evaporation crucible, there is an "auto purification" of the product [36].

In order to try to prevent polymer degradation during deposition, we have measured the temperature of the evaporation boat, using a copper-constantan thermocouple, the weld of the thermocouple being clamped between the body of the crucible and its lid. The thin films structures were analyzed by $\mathrm{X}$ ray diffraction $(\mathrm{XRD})$ by a Siemens D5000 diffractometer using $\mathrm{K} \alpha$ radiation from $\mathrm{Cu}\left(\lambda_{\mathrm{Ka}}=0.15406 \mathrm{~nm}\right)$.

The optical measurements were carried out at room temperature using a Carry spectrometer. The film optical density was measured at wavelengths of 1 to $0.30 \mu \mathrm{m}$.

AFM images on different sites of the film were taken ex-situ at atmospheric pressure and room temperature. All measurements have been performed in tapping mode (Nanowizard JPK Instrumens), Classical Silicon-SPMSensor were used (NCHR, NanoWorld $\left.{ }^{\circledR}\right)$. The average force constant and resonance were approximately $14 \mathrm{~N} / \mathrm{m}$ and $330 \mathrm{~Hz}$, respectively. The cantilever was excited at its resonance frequency. The surface roughness $\mathrm{Rq}$ (root mean square roughness) of each polymeric surface over the different buffer layer was evaluated with AFM software.

The electrochemical work was performed on a Voltamaster model CV $50 \mathrm{~W}$ potenciostat/galvanostat, using a conventional three-compartment, three-electrode cell, and a polycrystalline platinum disk $\left(0.07 \mathrm{~cm}^{2}\right.$ geometric area $)$ as working electrode. The counter electrode was a coiled Pt wire of large area, separated from the electrolytic solution by a sintered glass. The reference electrode was a $\mathrm{Ag} / \mathrm{AgCl}$ electrode that matches the potential of the saturated calomel electrode (SCE). Then all potentials quoted in the electrochemical section, are referred to the SCE. The electro-polymerization of each monomer ( 0.01 $\mathrm{mol} \cdot \mathrm{L}^{-1}$ ) was carried out in anhydrous acetonetrile using tetrabutylammonium hexafluorophosphate $\left(\mathrm{TBAPF}_{6}, 0.1\right.$ $\mathrm{mol} \cdot \mathrm{L}^{-1}$ ) as supporting electrolyte. All the system was kept under argon atmosphere and all measurements were performed at room temperature.

Electrical characterizations were performed with an automated I-V tester, in the dark and under sun global AM 1.5 simulated solar illumination. Performances of photovoltaic cells were measured using a calibrated solar simulator (Oriel $300 \mathrm{~W}$ ) at $100 \mathrm{~mW} / \mathrm{cm}^{2}$ light intensity adjusted with a PV reference cell $\left(0.5 \mathrm{~cm}^{2}\right.$ CIGS solar cell, calibrated at NREL, USA). Measurements were performed at an ambient atmosphere. All devices were illuminated through TCO electrodes [37].

In order to determine the effect of the ABL on the different ED film conductivity, we have investigated the $\mathrm{J}-\mathrm{V}$ characteristics of hole-only devices with $\mathrm{MoO}_{3}$ or $\mathrm{CuI}$ ABL. These devices were grown using high workfunction electrode buffer layers. The hole only devices were fabricated with high work function $\mathrm{MoO}_{3}$, which is well known to be a hole injector (collector) and a blocking electron layer. Hole only devices have been made using the same ITO covered glass substrate than those used to grow OPV cells. After deposition of the ABL, an ED film thick of $15 \mathrm{~nm}$ has been deposited. Then the organic film has been covered with a $\mathrm{MoO}_{3}$ film thick of $4 \mathrm{~nm}$. Finally aluminium has been used as top electrode.

We have also proceeded to thermal gravimetric analysis (TGA) of the different EDs to determine changes in weight in relation to temperature, in order to check the stability of the polymers at the temperature used for their sublimation. TGA analyses were carried out in a 951 Thermogravimetric Analyser TA-9900 in nitrogen atmosphere (flow rate $=100 \mathrm{~mL} / \mathrm{min}$ ) at a heating rate of $10^{\circ} \mathrm{C} / \mathrm{min}$.

\section{Experimental Results}

\subsection{NMR Characterization of Monomers and Polymers}

To determine the polymerization positions, the polymers were characterized using NMR spectroscopy. The NMR signal that disappears in the NMR of polymer indicates. the growth position on the chain [38].

P4,2FA shows in both NMR spectra Figure 2 the signals a and a' attributed to becenic protons, however, additional signals appears over $7.3 \mathrm{ppm}$, this correspond to quinoids protons (aniline and furane protons) [38]. The signals $\mathrm{c}$ and $\mathrm{d}$ in the NMR spectra of monomer remains after the polymerization process but, the signal $g$ of the monomer (proton of carbon 5 of furane ring in monomer numeration) disappears after the polymerization. The 
signal $\mathrm{d}$ is attributed to linkage of furane-furante ring as Lère-Porte et al. have reported previously $[38,39]$. This results indicates that the polymerization of 4,2FA occurs by carbon 5 of furane ring and exist only one furanefurane linkeage because the linkage Nitrogen-Nitrogen of aniline rings is not possible in this kind of polymerizetion. In the case of 4,3FA the NMR spectra Figure 3 show that after the polymerization of monomer the signals $\mathrm{c}$ and $\mathrm{d}$ disappears and the signal $\mathrm{b}$ remains which $\mathrm{h}$ indicates that the polymerization occurs by two positions of furane ring (carbon 2 and 4 ) of random forms. This produces a branched polymer without presence of quinoids units. This fact prevents a decrease of molecular band gap.

In the case of 4,2TA and 4,3TA the same synthetic behavior is observed as previously we have reported [38]. In this sense the positions of polymerization of 4,2TA, 4,3TA, 4,2FA and 4,3FA is the same respectively i.e. $4,2 \mathrm{TA}$ and 4,2FA polymerized by position 5 of heteroaryl ring which produces a non branched polymer. By the other hand 4,3TA and 4,3FA have two positions of

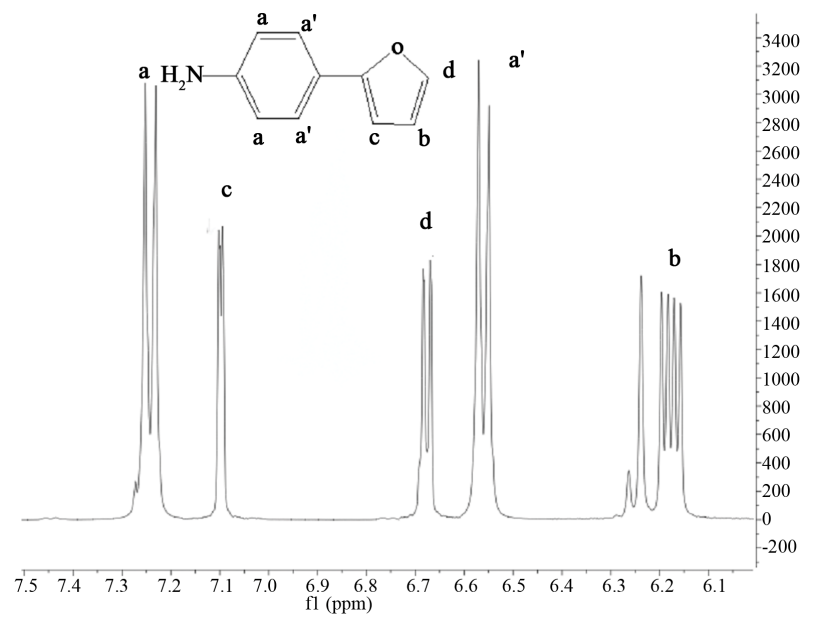

(a)

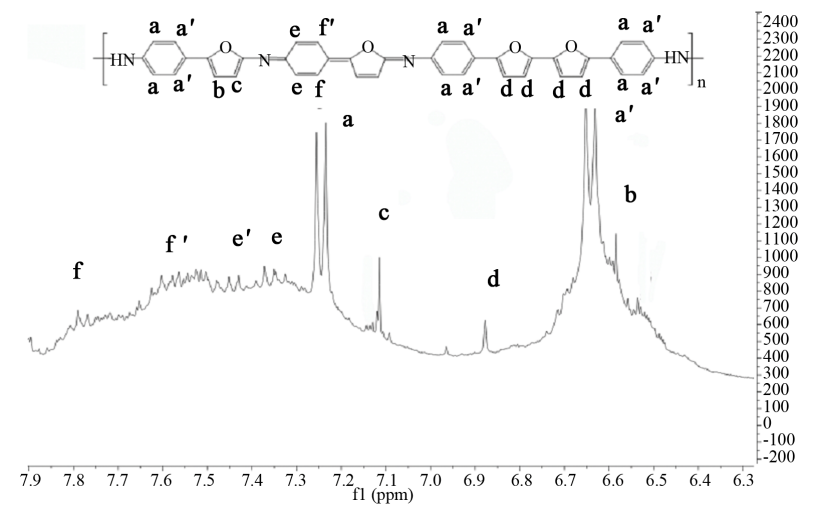

(b)

Figure 2. ${ }^{1} \mathrm{H}$-NMR spectra in the aromatic range for (a) the monomer 4,2FA and (b) the polymer P4,2FA.

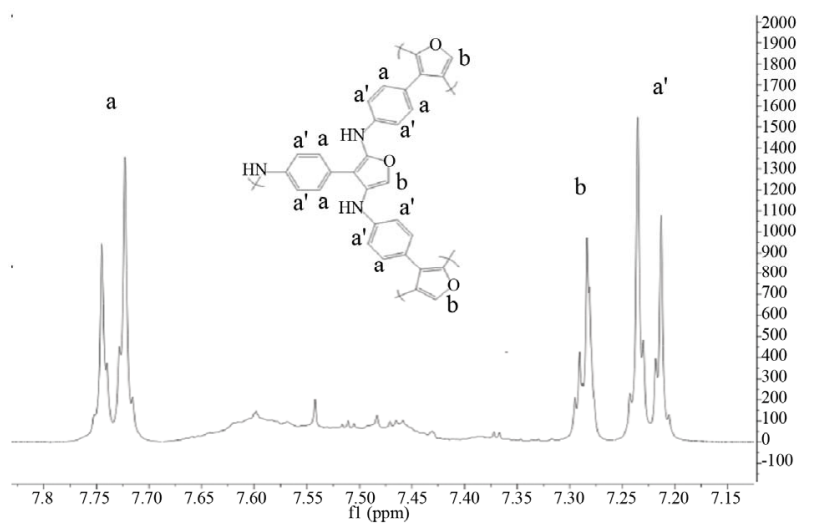

(a)

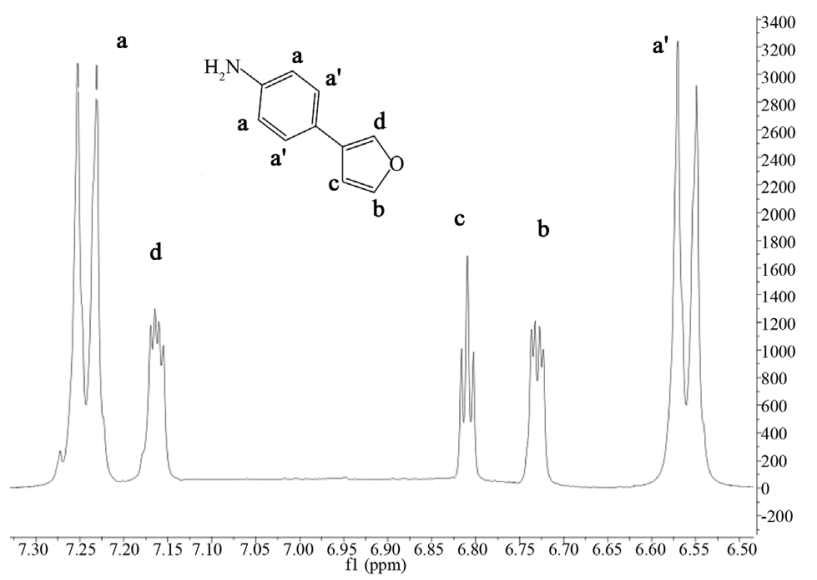

(b)

Figure 3. ${ }^{1} \mathrm{H}$-NMR spectra in the aromatic range for (a) the Polymer P4,3FA and (b) the monomer P4,3FA.

polymerization (carbon 2 and 4 of heteroaryl ring) which produces a branched structure. The NMR spectra of $4,2 \mathrm{TA}$ and 4,3TA have been previously reported by Zamora et al. [38]. These results suggest that in these polymers the Sulfur or Oxygen atoms of heteroaryl ring have no significant influence in the polymerization process.

\subsection{Thermal Gravimetric Analysis and Electrochemical Characterization of the Polymers}

Before polymer thin film deposition by sublimation under vacuum, the thermal stability of the different polymers used has been studied by TGA measurements. The results are presented in Figure 4. It can be seen that the weight loss of all the polymers is less than $10 \%$ up to $250^{\circ} \mathrm{C}$. However the stability depends on the polymers. The P4,2TA is the more stable, with only $5 \%-6 \%$ of losses of weight at $300^{\circ} \mathrm{C}$, while $\mathrm{P} 4,2 \mathrm{FA}$, which is the less stable, has already lost $25 \%$ of it weight for the same temperature. Therefore in order to prevent the breaking 


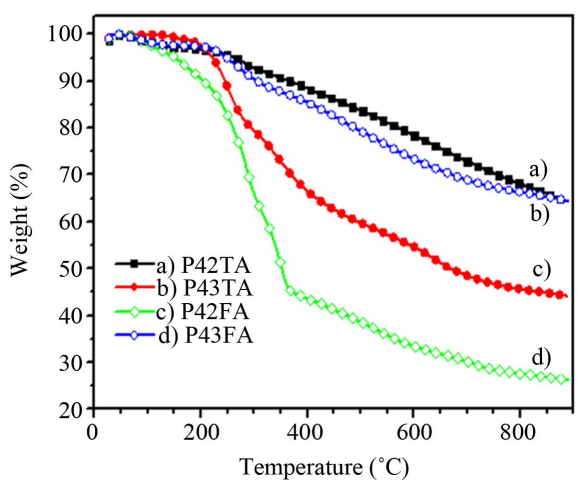

Figure 4. TGA of the different EDs: (a) P4,2TA, (b) P4,3TA, (c) P4,2FA and (d) P4,3FA.

of polymer chains during the deposition process the temperature was limited at $190^{\circ} \mathrm{C}$.

On the other hand, in the case of solar cells, after photon absorption and exciton creation, the efficiency of the photo induced charge separation is a key problem. Whatever the structure used, bilayer or bulk heterojunction, the donor and acceptor should have their relative electron affinity (LUMO) and ionisation potential (HOMO) well adapted. The electron affinity of the donor is smaller than that of the acceptor, while the ionisation potential of the acceptor must be significantly greater than that of the donor. When the donor is excited, the electron promoted to the LUMO will lower its energy by moving to the LUMO of the acceptor. The band offset at the organic hetero-interface between the electron-donor material and the electron-acceptor material tends to separate the exciton diffusing to that interface into an electron in the acceptor and a hole in the donor material. Therefore, the knowledge of the HOMO and LUMO of the organic material is very important. When the organic material shows a one electron reversible reduction and oxidation wave, cyclic voltammetry (CV) is recognised as an important technique for measuring band gaps, electron affinities (LUMO) and potential ionisation (HOMO). The oxidation process corresponds to removal of charge from the HOMO energy level whereas the reduction cycle corresponds to electron addition to the LUMO. Moreover, the potential difference $\mathrm{Eg}=\mathrm{LUMO}-\mathrm{HOMO}$ can be used to estimate the energy gap of the polymer. Therefore, the HOMO and LUMO energy of the different EDs used in the present work have been estimated before their use in OPVCs. The energy level of the normal hydrogen electrode (NHE) is situated $4.5 \mathrm{eV}$ below the zero vacuum energy level. To estimate the HOMO and LUMO energy, the slope change of the anodic and cathodic current respectively were determined. These values corresponds to the onset oxidation potential $\left(\mathrm{E}_{\mathrm{ox}}\right)_{\text {on }}$, and onset reduction potential $\left(\mathrm{E}_{\text {red }}\right)_{\text {on }}$ and correlates linearly with the HOMO and LUMO energy, with a correction factor of $4.4 \mathrm{eV}[40,41]$ :

$$
\begin{aligned}
& \mathrm{E}(\mathrm{HOMO})=-\left(\left(\mathrm{E}_{\text {ox }}\right)_{\text {on }}+4.4\right) \mathrm{eV} \\
& \mathrm{E}(\mathrm{LUMO})=-\left(\left(\mathrm{E}_{\text {red }}\right)_{\text {on }}+4.4\right) \mathrm{eV}
\end{aligned}
$$

The different HOMO and LUMO values deduced from cyclic voltammetry measurement are reported in Table 1, polymeric responses were assessed applying a perturbation to the modified electrode in a monomer-free solution of supporting electrolyte $\left(0.1 \mathrm{~mol} \cdot \mathrm{L}^{-1} \mathrm{TBAPF}_{6}\right)$ in anhydrous acetonitrile finding in all cases a p-type and n-type doping. No chemical degradation of these states was observed after 10 cycles.

\subsection{OPVCs Performances}

The performances of the cells using the different EDs are presented in Figure 5, the ABL being used as a parameter. Then, in order to understand the different behaviours, the multilayer structures ITO/ABL/ED have been characterized by XRD, AFM and optical measurements.

Table 1. Optical $(E g)$ and electrochemical $\left(E_{0}\right)$ band gap of the different EDs. Their HOMO and LUMO values deduced from electrochemical measurements are also reported.

\begin{tabular}{ccccc}
\hline ED & P4,2TA & P4,2FA & P4,3TA & P4,3FA \\
\hline Eg $(\mathrm{eV})$ & 1.55 & 1.4 & 2.15 & 2.0 \\
$\mathrm{E}_{0}(\mathrm{eV})$ & 1.5 & 1.48 & 2.2 & 2.14 \\
HOMO $(\mathrm{eV})$ & -4.9 & -5.16 & -5.1 & -5.36 \\
LUMO $(\mathrm{eV})$ & -3.4 & -3.68 & -2.9 & -3.22 \\
\hline
\end{tabular}

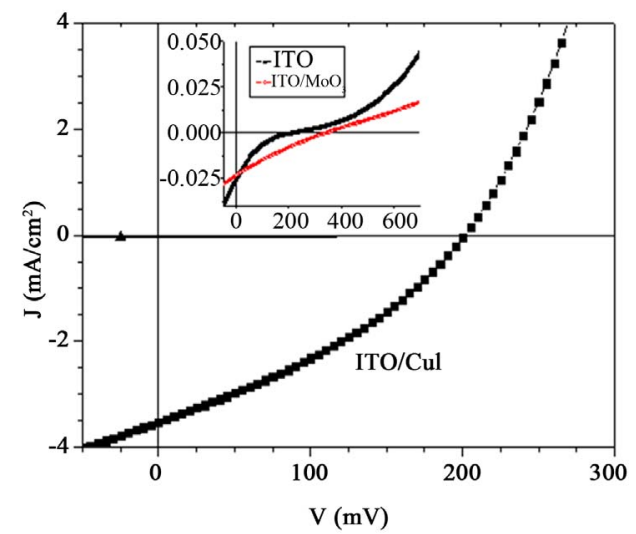

Figure 5. Typical J-V characteristics of ITO/ABL/P42TA/ $\mathrm{C}_{60} / \mathrm{BCP} / \mathrm{AI}$ structure, with $\mathrm{ABL}=\mathrm{ITO} / \mathrm{CuI}$ under illumination of AM1.5 solar simu- lation $\left(100 \mathrm{~mW} / \mathrm{cm}^{2}\right.$. Inset: enhanced $\mathrm{J}-\mathrm{V}$ characteristics of the cells using ABL without $\operatorname{CuI}\left(\operatorname{ITO}(\bullet), \operatorname{ITO} / \mathrm{MoO}_{3}\right)$. 
Typical results for the four OPVCs configuration used are presented in Figure 5, in the case of P4,2TA as ED. The corresponding values of the short circuit currents (Jsc), open circuit voltages (Voc), fill factors (FF) and cells efficiency $(\eta)$ are given in Table 2 . The cells presented in each figure have been deposited in the same run. It can be seen that the presence of $\mathrm{CuI}$ in the $\mathrm{ABL}$ improve strongly the OPVC performances. This improvement is mainly due to the fact that Jsc is more than one order of magnitude higher in presence of CuI. There is also a significant improvement of $\mathrm{FF}$, while there is no enhancement of Voc Table 2. All these results in a power cell efficiency (PCE) two orders of magnitude higher when $\mathrm{CuI}$ is used as ABL. Even if the overall efficiencies are slightly smaller, the same effect is obtained in the case of P4,2FA (Table 2).

Must be noted that when P4,3TA and P4,3FA are used as ED, the PCE of the cells is very small, however the same improvement in presence of $\mathrm{CuI}$ is achieved, from around $2.5 \times 10^{-3} \%$ and $2 \times 10^{-4} \%$ without $\mathrm{CuI}$ to $2.5 \times$ $10^{-2} \%$ and $3 \times 10^{-3} \%$ with $\mathrm{CuI}$ in the case of P4,3TA and $\mathrm{P} 4,3 \mathrm{FA}$, respectively. It can be concluded that the solar cell performances are far better when the ITO is recovered with CuI. As it can be seen in Table 2, $\mathrm{MoO}_{3}$, in the case of P4,2TA, improve the OPVC performance and since it is well known that $\mathrm{MoO}_{3}$ allows achieving a good band matching between the ITO anode and the HOMO of the ED, whatever the HOMO value [42], we have tried to optimise the PCE of the OPVCs using a double $\mathrm{ABL}, \mathrm{MoO}_{3} / \mathrm{CuI}$ in our last samples. One can see that this double $\mathrm{ABL}$ allows improving significantly the PCE.

\subsection{Characterization of the ITO/ABL/ED Structures}

In order to understand the origin of the strong improve-

Table 2. Photovoltaic performance data under AM1.5 conditions of devices using P4,2TA or P4,2FA as ED with different anodes.

\begin{tabular}{cccccc}
\hline \multirow{2}{*}{ ED } & Anode & $\begin{array}{c}\text { Jsc } \\
\left(\mathrm{mA} / \mathrm{cm}^{2}\right)\end{array}$ & Voc (V) & $\mathrm{FF}(\%)$ & $\eta(\%)$ \\
\hline \multirow{4}{*}{ P4,2TA } & $\mathrm{ITO}$ & 0.024 & 0.20 & 14 & $6.7 \times 10^{-4}$ \\
& $\mathrm{ITO} / \mathrm{MoO}_{3}$ & 0.023 & 0.34 & 21 & $1.6 \times 10^{-3}$ \\
& $\mathrm{ITO} / \mathrm{CuI}$ & 2.55 & 0.20 & 33.5 & 0.17 \\
& $\mathrm{ITO} / \mathrm{MoO}_{3} / \mathrm{CuI}$ & 4.13 & 0.20 & 33 & 0.23 \\
& $\mathrm{ITO}$ & 0.021 & 0.42 & 20 & $1.7 \times 10^{-3}$ \\
\multirow{2}{*}{ P4,2FA } & $\mathrm{ITO} / \mathrm{MoO}_{3}$ & 0.017 & 0.47 & 16.5 & $1.3 \times 10^{-3}$ \\
& $\mathrm{ITO} / \mathrm{CuI}$ & 0.94 & 0.47 & 21 & 0.10 \\
& $\mathrm{ITO} / \mathrm{MoO}_{3} / \mathrm{CuI}$ & 0.88 & 0.36 & 40.5 & 0.13 \\
\hline
\end{tabular}

ment of the OPVCs performances induced by the presence of a $\mathrm{CuI} \mathrm{ABL}$, the structures $\mathrm{ITO} / \mathrm{ABL} / \mathrm{ED}$, with $\mathrm{ABL}=\mathrm{MoO}_{3}, \mathrm{CuI}$, or no $\mathrm{ABL}$ and $\mathrm{ED}=\mathrm{P} 4,2 \mathrm{TA}, \mathrm{P} 4,2 \mathrm{FA}, \mathrm{P} 4,3 \mathrm{TA}, \mathrm{P} 4,3 \mathrm{FA}$, have been submitted to XRD, AFM, optical and hole only electrical characterizations.

All EDs deposited onto the different ABLs have been studied by XRD diffraction. However, well resolved diffraction peaks have been obtained only with P4,2FA. In that case, as it can be seen in Figure 6, the intensity of the diffraction peaks depends on the ABL used. The presence of $\mathrm{CuI}$ induces a significant improvement of the intensity of peaks. Also, some new diffraction peaks are visible. Therefore, the presence of $\mathrm{CuI}$ induces, not only an improvement of the crystallinity of the deposited films, but also the presence of two crystalline phases of the organic material or at least two different orientations of the crystallites.

This show that, the $\mathrm{CuI}$ ABL has a clear templating effect on P4,2FA, it induces some ordered growth of the organic material. Even if not easily visible in the case of the others EDs, the films being often highly disordered, $\mathrm{CuI}$ could also modify the growth properties of the organic films. As a mater of fact, this order modification is corroborated by the AFM study. Indeed, the AFM study shows that, even if the root mean square roughness (Rq) of the surface is not strongly modified by the ABL configuration Table 3, the CuI ABL induces a significant decrease of the $\mathrm{Rq}$ value, which results in a clear modification of the surface morphology of the polymer film Figure 7.

This effect, which in the case of P4,2FA Figure 7 can be correlated to the modification of the crystalline order in the film, is also clearly visible in the case of the others polymers, as shown for P4,2TA in previous works of Zamora et al. [38]. Therefore it can be inferred that, here also, the order of the organic molecules is modified by

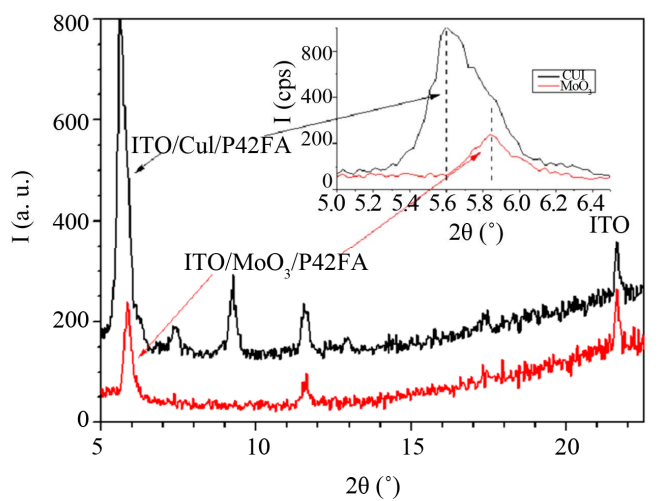

Figure 6. X-ray diffraction diagrams of the ITO/ABL/ P4, 2FA structures with ITO, $\mathrm{CuI}, \mathrm{MoO}_{3} / \mathrm{CuI}$ as $\mathrm{ABL}$. 
Table 3. Variation of the Rq (root mean square roughness) for the four EDs with the different ABLs.

\begin{tabular}{cccc}
\hline \multirow{2}{*}{ ED } & \multicolumn{3}{c}{$\mathrm{ABL}$} \\
\cline { 2 - 4 } & $\mathrm{No} \mathrm{ABL}$ & $\mathrm{MoO}_{3}$ & $\mathrm{CuI}$ \\
\hline P4,2TA & 13.33 & 15.31 & 8.76 \\
P4,2FA & 13.85 & 15.66 & 11.81 \\
P4,3TA & 16.31 & 15.14 & 13.06 \\
P4,3FA & 16.67 & 15.82 & 12.63 \\
\hline
\end{tabular}
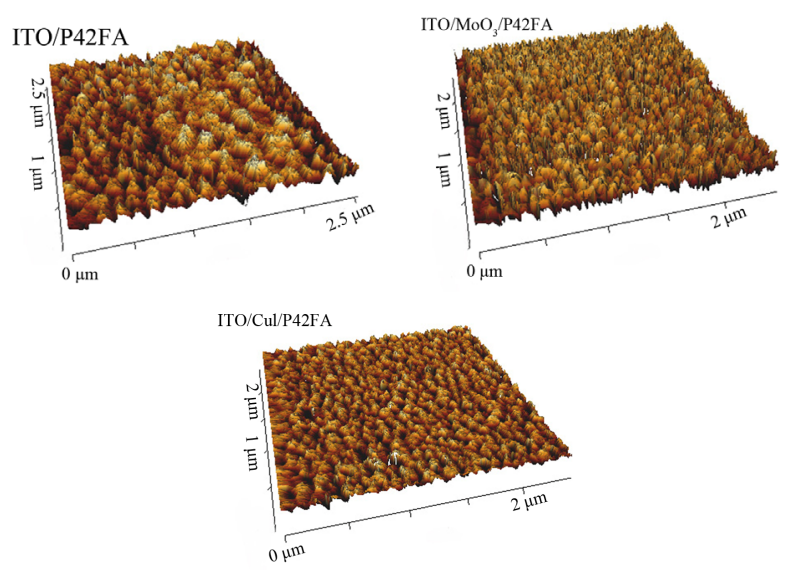

Figure 7. TM-AFM images of P4,2FA, (15 nm thick) deposited onto ITO ITO $/ \mathrm{MoO}_{3} / \mathrm{CuI}$ and ITO/CuI .

the $\mathrm{CuI}$ ABL.

The influence of the ABL on the optical absorbance has been probed. From the example of P4,2TA visualised in Figure 8, it can be seen that there is no clear shift of the absorption spectrum of the film, there is only a slight increase of the absorption in presence of $\mathrm{CuI}$ mainly for the small band situated at $440 \mathrm{~nm}$.

The J-V characteristics of the hole only devices are shown in Figure 9. It shows typical curves $\log (\mathrm{J})$ against $\log (\mathrm{V})$ plots obtained when injecting holes through the ITO contact. Charge transport in these devices is limited to holes. Electron injection from the aluminium electrode can be neglected, due to the large electron barrier due to the $\mathrm{MoO}_{3}$ interlayer. The devices using $\mathrm{CuI}$ and

$\mathrm{MoO}_{3} / \mathrm{CuI} \mathrm{ABL}$ show largest current density at the same driving voltages as compared to the devices using $\mathrm{MoO}_{3} \mathrm{ABL}$. Clearly the conductivity is enhanced by nearly an order of magnitude when a $\mathrm{CuI}$ or $\mathrm{MoO}_{3} / \mathrm{CuI}$ $\mathrm{ABL}$ is used on the place of the $\mathrm{MoO}_{3} \mathrm{ABL}$. For instance when the applied voltage is $10 \mathrm{mV}$, the current density with $\mathrm{MoO}_{3} \mathrm{ABL}$ is $0.047 \mathrm{~mA} / \mathrm{cm}^{2}$, while it is $0.35 \mathrm{~mA} / \mathrm{cm}^{2}$ with $\mathrm{CuI}$ ABL.

Therefore, it is clear that the presence of a $\mathrm{CuI}$ layer below the organic film induces significant modifications of these organic films, which result in a strong improve- ment of the solar cells performances in the presence of CuI ABL.

\section{Discussion}

After First of all, following the works of Kovacik et al. and E. Nasybulin et al. [30,31], we have checked the temperature of the polymer crucible in order to avoid polymer molecule destruction during the sublimation. Since the mass loss of P4,2TA is bellow $5 \%$ at $190^{\circ} \mathrm{C}$ we can conclude that this polymer is not destroyed during the deposition. Moreover, even if there is, probably, some decrease of the molecular weight due to the sublimation process, this decrease is not sufficient to modify strongly the optical properties of the polymer, since the absorption domain of the films is in good agreement with absorption deduced from the band gap estimated by electrochemistry. If this is true for $\mathrm{P} 4,2 \mathrm{TA}$, the case of $\mathrm{P} 4,2 \mathrm{FA}$ is different. Actually at $190^{\circ} \mathrm{C}$ its weight loss is nearly $5 \%$, which means that there is probably some degradation of the polymer, at least a strong decrease of the chain lengths and/or opening of furan ring. It is know that furan ring is less stable than thiophene ring [43]. When furane ring is opened two ketones units are formed (dicarbonyl moieties). This chemical modification pro-

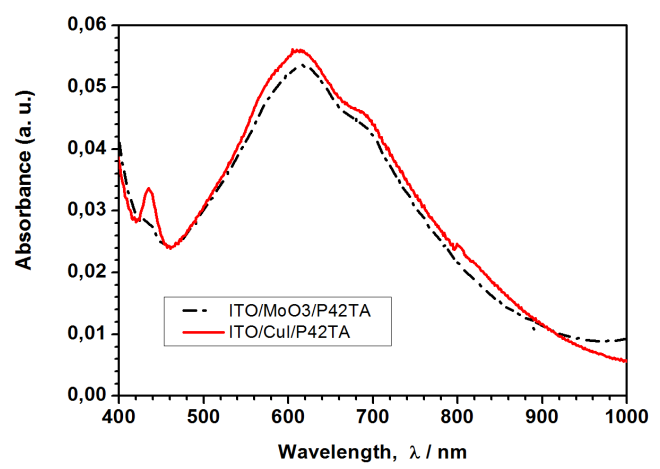

Figure 8. Variation of the optical density of the ITO/ABL/ P4,2TA structures with the ABL.

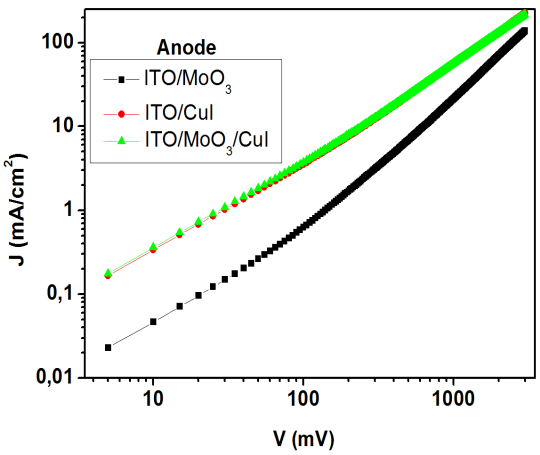

Figure 9. Log-log plot of the current density-voltage curves of the hole only devices for different ABLs. 
duces more flexibility in the polymeric chains and a lost of conjugation due to the decrease of quinoids and heteroaryl units. Moreover, aniline-thiophene units show more thermal stability in a greater range of temperature due to thiophene ring, which is more aromatic than furane. These degradations of the chain length or furan ring-opening decrease the photovoltaic yield. Therefore P4,2FA films correspond probably to oligomer films. This can explain the crystallization of the films, since films of oligomers crystallize easier than polymer films (Figure 6). Therefore if the partial destruction of the polymer chain during the heating process of $\mathrm{P} 4,2 \mathrm{FA}$ can explain that better PCE are achieved with OPVCs using more stable polymer, the fact that it crystallize more easily help us to put in evidence the effect of the different $\mathrm{ABL}$ on the growth properties of the films. When deposited onto $\mathrm{CuI}$ it is clear that the crystallization of P4,2FA is different from that achieved when it is deposited onto $\mathrm{MoO}_{3}$. The intensity of the diffraction peaks is far higher than that obtained when the films are deposited onto $\mathrm{MoO}_{3}$, which testifies of a better crystalinity of the films deposited onto $\mathrm{CuI}$. After decomposition of the strongest diffraction peak of each diagram, it can be seen that the grain size of the crystallites is more or less the same in each films since the full width at half maximum is around 0.20 degree. This means that the ratio crystallized phase/amorphous phase is higher when the film is deposited onto CuI. Moreover the new peaks visible in the diffraction diagram of the films deposited onto $\mathrm{CuI}$ show that a new crystalline phase or at least a new grain orienttation is induced by the $\mathrm{CuI}$ under layer. The different characterizations of the structures ITO/ABL/ED have shown that $\mathrm{CuI}$ modifies the properties of the organic films. The XRD and AFM studies show that the order in the films is significantly improved by the $\mathrm{CuI}$ bottom layer. If these modifications have not a broad impact on the optical properties of the films they improve signifycantly their conductivity. As a matter of fact, if $\mathrm{CuI}$ does not induce systematically the crystallization of the polymers, it improves the order of the molecules in the films, which justifies the improvement of the conductivity of the films. It is well known that a limiting factor of the PCE in organic OPVCs is the small conductivity of the organic films. Therefore an increase of this conductivity induces higher short circuit current density and therefore better PCEs.

Another important parameter is the open circuit voltage Voc, it is well known that its maximum value corresponds to the difference between the HOMO of the ED and the LUMO of the acceptor. Therefore, following the results indicated in Table 1 the Voc obtained with P4,2FA must be higher than that achieved with P4,2TA. It can be seen in Table 2 that it is actually the case. How- ever, the PCE of achieved with the cells using P4,2TA as ED is higher than that achieved with P4,2FA, which is due to the smaller Jsc measured. Such disappointing result must be related to the fact that, as shown by the TGA study, P4,2FA is less stable than P4,2TA and it undergoes probably damages during its deposit.

Nevertheless, whatever the polymer used as electron donor, it is clear that $\mathrm{CuI}$ improved strongly the OPVCs performances. Since it is known that a $\mathrm{MoO}_{3}$ anode buffer layer allows obtaining good band matching with electron donors, which HOMO value is around $5 \mathrm{eV}$ [42], it is clear from the present study that if this condition is necessary it is not sufficient in the case of the polymers studied in the present work. He is necessary furthermore to use an anode buffer layer which improves the morphology and therefore the conductivity of the polymer. In the present case, we show that $\mathrm{CuI}$ is very efficient as templating layer. Theses differences in organic film morphology on different substrates are usually attributed to the different interaction between the organic material and the surface of the substrates. Often it is proposed that when the interaction organic molecule-substrate is stronger than the molecule-molecule interaction, the films adopt a lying down configuration (2 dimensions growth of the film). If the molecule-substrate interaction is weak, the molecule-molecule interaction dominates and the molecules adopt a standing up configuration (three dimension growth of the film). For instance, different studies have been done on the influence of the substrate on the molecular orientation of $\mathrm{CuPc}[44,45]$. In the present study, we show that the presence of a thin $\mathrm{CuI}$ layer onto the ITO allows controlling the morphology of the polymer films. It has been already shown that $\mathrm{CuI}$ and other copper halides can interact easily with organic molecules [46-49]. For instance, complex formation between $\mathrm{CuI}$ and organic molecules leads to different $\pi$ stacking copper halide motifs [46]. More precisely, there is complex formation between copper (I) iodine and nitrogen-donor of the organic molecules. Also, it is well-established that the pymSH/pymS ${ }^{-}$and bis (2-pyrimidyl)disulfide (pym2S2) ligands are good coordinating ligands toward soft Lewis acids such as $\mathrm{Cu}$ (I) and it as been shown that, the solvothermal reactions between pyrimidinedisulfide (pym2S2) and $\mathrm{CuI}$ in $\mathrm{CH}_{2} \mathrm{Cl}_{2}: \mathrm{CH}_{3} \mathrm{CN}$ lead to the formation of [Cu11I7(pymS)4]n (pymSH = pyrimidine-2(1H)-thione) [47]. Another example is presented in [48] where it is shown that solution reaction of $\mathrm{CuI}$ and the ligand L((3-bpfob) [L: 1,3-bis(nicotinoyl) o-phenylenediamine] led to the formation of a novel coordination polymer $[\mathrm{CuI}(3-\mathrm{bpfob})] \mathrm{n}$ that exhibited an unusual one-dimensional helical structure. All these examples show that the $\mathrm{CuI}$ exhibits a high tendency to react with an atom donor of organic molecules (as nitrogen, sulphur and oxygen 
atoms) when they are in contact.

\section{Conclusion}

In order to discuss the effect of $\mathrm{CuI}$ on the properties of the polymer films and their corresponding OPVCs, cells with $\mathrm{CuI}$ and also with $\mathrm{MoO}_{3}$ or without $\mathrm{ABL}$ have been probed. It is shown that the $\mathrm{CuI} A B L$ thin film induces significant improvement of the structural properties of the oligomers, which increases the order in the deposited films and allows strong enhancement of the OPVCs performances due to possible strong $\mathrm{Cu}$-polymer interaction on the ABL surface like pyrimidine- $\mathrm{Cu}$ interaction. By the other hand the EDs show is thermally stable under $190^{\circ} \mathrm{C}$ and the rate of degradation does not appear to significantly affect the optical properties of the polymer. The PCE achieved with the better polymer of the four EDs of the aniline-heteroaryl family studied in the present work is of the same order of magnitude as those achieved by Kovacik et al. and E. Nasybulin et al. [30,31] with the polythiophene, which is very promising and justifies further working with these materials.

\section{Acknowledgements}

The authors thank FONDECYT financial support through project 1095156. P.Z. acknowledge the doctoral scholarship 21090478, doctoral scholarship support 24110046, granted to conduct this research and ECOS CONICYT project No.C09E02

\section{REFERENCES}

[1] S. Bhadra, N. Singha and D. Khastgir, "Effect of Aromatic Substitution in Aniline on the Properties of Polyanil," European Polymer Journal, Vol. 44, No. 6, 2008, pp. 1763-1770.

[2] Z. Liu, W. Guo, D. Fu and W. Chen, "p-n Heterojunction Diodes Made by Assembly of ITO/Nano-Crystalline TiO 2/Polyaniline/ITO," Synthetic Metals, Vol. 156, No. 5, 2006, pp. 414-416.

[3] J. Gao, J. M. Sansinena and H. L. Wang, "Chemical Vapor Diven Polyaniline Sensor/Actuators," Synthetic Metals, Vol. 135-136, No. 4, 2003, pp. 809-810.

[4] A. Bishop and P. Gouma, "Leuco-Emeraldine Based Polyaniline-Poly-Vinyl-Pyrrolidone Electrospun Composites and Bio-Composites: A Preliminary Study of Sensing Behaviour," Reviews on Advanced Materials Science, Vol. 3, No. 10, 2005, pp. 209-214.

[5] J. Upadhyay, P. Gaston, A. A. Levy and A. Wassermann "Cationic Polymerisation of a Bicyclopentyl Derivative: Mechanism of Formation of Deeply Coloured, Electrically Conducting Polymers," Journal of The Chemical Society, Vol. 593, 1965, pp. 3252-3266. doi:10.1039/jr9650003252

[6] C. F. Blakely, R. J. Gillespie, L. Roubinek, A. Wasser- mann and R. F. M. White, "Conversion of Cyclopentadiene into New Bicyclopentyl Derivatives; Structure Determination with the Help of Proton Magnetic Resonance Spectroscopy," Journal of The Chemical Society, Vol. 374, 1961, pp. 1939-1945. doi:10.1039/jr9610001939

[7] J. Upadhyay, J. B. G. Wallace and A. Wassermann, "Proton Accetor Properties and Electrical Conductance of Deeply Coloured Cyclopentadiene Polymers," Polymer, Vol. 7, No. 9, 1966, pp. 465-468.

[8] P. V. French, L. Roubinek and A. Wassermann, "Preparation and Properties of Deeply Coloured, Electrically Conducting Polymers," Journal of The Chemical Society, Vol. 376, 1961, pp. 1953-1963. doi:10.1039/jr9610001953

[9] M. Armour, A. G. Davies and A. Wassermann, "Colored Electrically Conducting Polymers from Furan, Pyrrole, and Thiophene," Journal of Polymer Science Part A, Vol. 5, No. 7, 1966, pp. 1527-1538.

[10] C. E. H. Bawn, C. Fitzsimmons and A. Ledwith, "Reactivity and Mechanism in the Cationicpolymerization of Isobutyl Vinyl Ether," Polymer, Vol. 12, No. 2, 1971, pp. 119-140.

[11] M. Talu, M. Kabasakolglu, F. Yildirin and B. Sari, "Electrochemical Synthesis and Characterization of Homopolymers of Polyfuran and Polythiophene and Bipolymer Films Polyfuran/Polythiophene and Polythiophene/Polyfuran," Applied Surface Science, Vol. 181, No. 1, 2001, pp. 51-60.

[12] I. Carrillo, E. Sanchez de la Blanca and M. J. GonzalezTejera, "Influence of the Electropolymerisation Time on the Nucleation Mechanism, Structure and Morphology of Polyfurane/Perchlorate Doped Films," Polymer, Vol. 42, No. 1, 2001, pp. 9447-9453. doi:10.1016/S0032-3861(01)00500-6

[13] M. Kabasakalo glu, M. Talu, F. Yildirim and B. Sari, "The Electrochemical Homopolymerization of Furan and Thiophene and the Structural Elucidation of Their Bipolymer Films," Applied Surface Science, Vol. 218, No. 1, 2003, pp. 85-97.

[14] F. C. Krebs, "A Review of Printing and Coating Techniques," Solar Energy Materials \& Solar Cells, Vol. 93, No. 4, 2009, pp. 394-412. doi:10.1016/j.solmat.2008.10.004

[15] J. C. Bernede, "Organic Photovoltaic Cells: History, Principle and Techniques," Journal of the Chilean Chemical Society, Vol. 53, No. 3, 2008, pp. 1549-1564.

[16] A. Godoy, L. Cattin, L. Toumi, F. R. Diaz, M. A del Valle and J. C. Bernede, "Effects of the Buffer Layer Inserted between the Transparent Conductive Oxide Anode and the Organic Electron Donor," Solar Energy Materials \& Solar Cells, Vol. 94, No. 4, 2010, pp. 648-654.

[17] J. C. Bernède, L. Cattin, M. Morsli and Y. Berredjem, "Ultra-Thin Metal Layer Passivation of the Transparent Conductive Anode in Organic Solar Cells," Solar Energy Materials \& Solar Cells, Vol. 92, No. 11, 2008, pp. 15081520.

[18] H. Wu, T. Song, Y. Jin and B. Sun, "High Performance Solar Cell Based on Ultra-Thin Oly(3-Hexylthiophene): 
Fullerene Film without Thermal and Solvent Annealing," Applied Physics Letters, Vol. 99, No. 14, 2011, pp. 735748.

[19] S. Han, S, W. S. Shin, M. Seo and D. Gupta, "Improving Performance of Organic Solar Cells Using Amorphous Tungsten Oxides as an Interfacial Buffer Layer on Transparent Anodes," Organic Electronics, Vol. 10, No. 5, 2009, pp. 791-797.

[20] M. T. Grenier, M. G. Helander and Z. B. Wang, "Highly Simplified Phosphorescent Organic Light Emitting Diode with $>20 \%$ External Quantum Efficiency at $>10,000 \mathrm{~cd} /$ m2v," Applied Physics Letters, Vol. 96, No. 21, 2010, pp. 213-230.

[21] S. Y. Park, H. R. Kim, Y. J. Kang, D. H. Kim and J. W. Kang, "Organic Solar Cells Employing Magnetron Sputtered p-Type Nickel Oxide Thin Film as the Anode Buffer Layer," Solar Energy Materials \& Solar Cells, Vol. 94, No. 12, 2012, pp. 2332-2346.

[22] P. Sullivan, T. S. Jones, A. J. Ferguson and S. Heutz, "Structural Templating as a Route to Improved Photovoltaic Performance in Copper Phthalocyanine/Fullerene $\left(\mathrm{C}_{60}\right)$ Heterojunctions," Applied Physics Letters, Vol. 91, No. 23, 2007, pp. 233114-233126.

[23] C. H. Cheng, J. Wang, G. T. Du and S. H. Shi, "Organic Solar Cells with Remarkable Enhanced Efficiency by Using a CuI Buffer to Control the Molecular Orientation and Modify the Anode," Applied Physics Letters, Vol. 97, No. 8, 2010, p. 83305.

[24] B. P. Rand, B. P. D. Cheyns, K. Vasseur, N. C. Giebink and S. Nothy, "The Impact of Molecular Orientation on the Photovoltaic Properties of a Phthalocyanine/Fullerene Heterojunction," Advanced Functional Materials, Vol. 22, No. 14, 2012, pp. 2987-2995.

[25] T. M. Kim, J. Kim, H. Shim and J. Kim, "High Efficiency and High Photo-Stability Zinc-Phthalocyanine Based Planar Heterojunction Solar Cells with a Double Interfacial Layer," Applied Physics Letters, Vol. 101, No. 11, 2012, p. 113301. doi: $10.1063 / 1.4748123$

[26] J. C. Bernède, A. Godoy, L. Cattin, F. R. Diaz, M. Morsili and M. A. del Valle, "Organic Solar Cells Performances Improvement Induced by Interface Buffer Layers," 1st Edition, M. D. Rugescu, In Tech, 2 February 2010.

[27] P. Kumar and S. Chand, "Recent Progress and Future Aspects of Organic Solar Cells," Progress in Photovoltaics: Research and applications, Vol. 20, No. 4, 2012, pp. 377-415.

[28] P. Peumans and S. R. Forrest, "Very-High-Efficiency Double-Heterostructure Copper Phthalocyanine/C60 Photovoltaic Cells," Applied Physics Letters, Vol. 79, No. 1, 2001, pp. 126-128. doi:10.1063/1.1384001

[29] W. Zeng, K. S. Yong, Z. M. Kam, F. Zhu and Y. Li, "Effect of Blend Layer Morphology on Performance of ZnPc: $\mathrm{C}_{60}$-Based Photovoltaic Cells," Applied Physics Letters, Vol. 97, No. 13, 2012, p. 133304.

[30] P. Kovacik, G. Sforazzini, A. G. Cook, S. M. Willis, P. S. Grant and H. E. Assender, "Vacuum-Deposited Planar Heterojunction Polymer Solar Cells," Applied Material Interfaces, Vol. 3, No. 1, 2011, pp. 11-15.
[31] E. Nasybulin, F. Feinstein and M. Cox, "Electrochemically Prepared Polymer Solar Cell by Three-Layer Deposition of Poly(3,4-Ethylenedioxythiophene)/Poly(2,2'Bithiophene)/Fullerene (PEDOT/PBT/C 60 )," Polymer, Vol. 52, No. 16, 2011, pp. 3627-3632.

[32] M. Can, S. Uzuna and N. Pekmez, "Chemical Polymerization of Aniline Using Periodic Acid in Acetonitrile," Synthetic Metals, Vol. 159, No. 14, 2009, pp. 1486-1490.

[33] S. E. Shaheen and C. J. Brabec, " $2.5 \%$ Efficient Organic Plastic Solar Cells," Applied Physic Letters, Vol. 78, No. 6, 2001, p. 841.

[34] L. Cattin, F. Dahou, Y. Lare, M. Morsli, R. Tricot, K. Jondo, A. Khelil, K. Napo and J. C. Bernède, " $\mathrm{MoO}_{3}$ Surface Passivation of the Transparent Anode in Organic Solar Cells Using Ultrathin Films," Journal of Applied Physic Letters, Vol. 105, No. 3, 2009, p. 34507.

[35] J. Ryu and C. Jang, "Supramolecular Reactor in Aqueous Environment: Aromatic Cross Suzuki Coupling Reaction at Room Temperature," Journal of Organic Chemistry, Vol. 70, No. 2, 2005, pp. 8956-8962.

[36] R. F. Slazman and J. Xue, "The Effects of Copper Phthalocyanine Purity on Organic Solar Cell Performance," Organic Electronics, Vol. 6, No. 5, 2005, pp. 242-450.

[37] Y. Berredjem, N. Karst, L. Cattin, A. Lakhdar-Toumi, A. Godoy, G. Soto, F. R. Diaz, M. Morsli and J. C. Bernede, "The Open Circuit Voltage of Encapsulated Plastic Photovoltaic Cells," Dyes and Pigments, Vol. 78, No. 2, 2008, pp. 148-156.

[38] P. P. Zamora, M. B. Camara, I. A. Jessop and F. R. Diaz, "Synthesis, Characterization, Morphology and Photovoltaic Properties of Aniline-Tiophene Based Polymers," International Journal of Electrochemical Science, Vol. 7, No. 7, 2012, pp. 8276-8288.

[39] J. J. Lère-Porte, E. Moreau and C. Torreilles, "Highly Conjugated Poly(Thiophene)s-Synthesis of Regioregular 3-Alkylthiophene Polymers and 3-Alkylthiophene/ Thiophene Copolymers" European Journal of Organic Chemistry, Vol. 2001, No. 7, 2001, pp. 1249-1258. doi:10.1002/1099-0690(200104)2001:7<1249::AID-EJO C1249>3.0.CO;2-F

[40] S. Admassie, O. Inganas, W. Mammo, E. Perzon and M. R. Andersson, "Electrochemical and Optical Studies of the Band Gaps of Alternating Polyfluorene Copolymers," Syntetic Metals, Vol. 156, No. 7, pp. 614-624.

[41] A. Charas, J. Morgado, J. Martinho, L. Alcácer, S. Lim, R. Friend and F. Cacialli, "Synthesis and Luminescence Properties of Three Novel Polyfluorene Copolymers," Polymer, Vol. 44, No. 6, 2003, pp. 1843-1455.

[42] J. C. Bernède, L. Cattin, S. Ouro Djobo, M. Morsil, S. R. B. Kanth, S. Patil, P. Leriche, F. R. Diaz and M. A. del Valle, "Influence of the Highest Occupied Molecular Orbital Energy Level of the Donor Material on the Effectiveness of the Anode Buffer Layer in Organic Solar Cells," Physica Status Solidi A, Vol. 208, No. 8, 2011, pp. 1989-1994.

[43] N. Abdelwahab, D. El-Nashar and D. Abd El-Ghaffar, "Polyfuran, Polythiophene and Their Blend as Novel Antioxidants for Styrene-Butadiene Rubber Vulcanizates," 
Materials and Design, Vol. 32, No. 1, 2011, pp. 238-245.

[44] H. Peisert, T. Schweiger, J. M. Auerthammer, M. Kkunpfer and M. S. Golden, "Order on Disorder: Copper Phthalocyanine Thin Films on Technical Substrates," Journal of Applied Physics, Vol. 90, No. 1, 2001, pp. 466-469.

[45] D. Qi, J. Sun, X. Gao and S. Wang, "Large Damage Threshold and Small Electron Escape Depth in X-ray Absorption Spectroscopy of a Conjugated Polymer Thin Film," Langmuir, Vol. 26, No. 1, 2006, pp. 165-172.

[46] A. J. Blake, N. R. Brooks, N. R. Champness, P. A. Cooke and M. Crew, "Copper(I) iodide Coordination NetworksControlling the Placement of $(\mathrm{CuI})_{\infty}$ Ladders and Chains within Two-Dimensional Sheets," Crystal Engineering, Vol. 2, No. 2, 1999, pp. 181-185.

[47] T. S. Lobana, S. Khanna, A. Castineiras, G. Hundal and Z.
Anorg, "Synthesis of an Unprecedented $\mathrm{Cu}^{\mathrm{I}}$ Polymer with Alternate $\mathrm{Cu}(\mu-\mathrm{S})_{2} \mathrm{Cu}$ and $\mathrm{Cu}(\mu-\mathrm{Cl})_{2} \mathrm{Cu}$ Cores Bridged by Pyridine-2-Carbaldehyde Thiosemicarbazone," Allgemeine Chemie, Vol. 636, No. 3, 2010, pp. 454-456.

[48] A. Gallego, O. Castillo, C. J. Gómez-García, F. Zamora and S. Delgado, "Electrical Conductivity and Luminescence in Coordination Polymers Based on Copper(I)Halides and Sulfur-Pyrimidine Ligands," Inorganic Chemistry, Vol. 51, No. 1, 2012, pp. 718-727.

[49] S. Li-Sha, W. Qing-Li and N. Yun-Yin, "Syntheses, Structure, and Photoluminescent and Thermal Properties of a Novel Coordination Polymer $[\mathrm{CuI}(3-\mathrm{bpfob})]_{\mathrm{n}}$ with One-Dimensional Helical Chain," Synthesis and Reactivity in Inorganic, Metal-Organic, and Nano-Metal Chemistry, Vol. 41, No. 9, 2011, pp. 1080-1085. 